\title{
1 Antifungal activity of silver nanoparticles during in-vitro culture of Stevia rebaudiana Bertoni
}

2 Marco A. Ramírez-Mosqueda ${ }^{1} \cdot$ Lino Sánchez-Segura $^{2} \cdot$ Sandra L. Hernández-Valladolid $^{3} \cdot$ Elohim Bello-Bello $^{4}$.

3 Jericó J. Bello-Bello ${ }^{5 *}$

4

$5 \quad{ }^{1}$ Colegio de Postgraduados Campus Córdoba, Km. 348 de la Carretera Federal Córdoba-Veracruz, Congregación

6 Manuel León, Amatlán de los Reyes, Veracruz, Mexico

$7 \quad 2$ Departamento de Ingeniería Genética, Unidad Irapuato, CINVESTAV-Irapuato. Libramiento Norte

8 Carr. Irapuato-León Km 9.6. Irapuato, Guanajuato, México.

$9 \quad{ }^{3}$ Agricultura Sustentable y Protegida, Universidad Tecnológica del Centro de Veracruz, Av. Universidad 350, Dos

10 caminos, 94910 Cuitláhuac, Veracruz, Mexico

$11{ }^{4}$ Laboratorio Nacional de Genómica para la Biodiversidad/Unidad de Genómica Avanzada, Centro de Investigación

12 y Estudios Avanzados, Instituto Politécnico Nacional, 36821. Irapuato, Guanajuato, México.

$13{ }^{5}$ CONACYT-Colegio de Postgraduados Campus Córdoba, Km. 348 de la Carretera Federal Córdoba-Veracruz,

14 Congregación Manuel León, Amatlán de los Reyes, Veracruz, Mexico

15

$16 *$ Authors for correspondence JJBB (jericobello@gmail.com)

17

18 Tel.: $+52(271) 7166000$

19

20

21

22 


\section{Abstract}

30 Contamination by fungi and bacteria during the in-vitro propagation of plants leads to considerable losses of biological

31 material and precludes phytosanitary certification. The anti-microbial effect of silver nanoparticles (AgNPs) may be

32 an alternative for the eradication of in-vitro contaminants. This study evaluated the microbicidal activity of AgNPs on

33 a recurrent fungus during the micropropagation of stevia (Stevia rebaudiana Bertoni). First, the fungus was isolated

34 and identified at a molecular level by the sequencing and analysis of the ITS4/ITS5 rDNA region. The results of the

35 phylogenetic analysis of various fungi species showed that the strain under study (16-166-H) belongs to the genus

36 Sordaria and is $86.74 \%$ similar to S. tomento-alba (strain CBS 260.78). Subsequently, the inhibition of the growth of

37 S. tomento-alba was tested under different concentrations of $\operatorname{AgNPs}\left(0,25,50,100\right.$, and $\left.200 \mathrm{mg} \mathrm{L}^{-1}\right)$, observing that

3850 and $100 \mathrm{mg} \mathrm{L}^{-1}$ achieve ca. 50\% growth inhibition ( $\mathrm{IC}_{50}$ ), while $200 \mathrm{mg} \mathrm{L}^{-1}$ produces a drastic inhibition. On the

39 other hand, the shape and size of AgNPs was examined using transmission electron microscopy (TEM), and the

40 transport and accumulation of AgNPs in S. tomento-alba cells were monitored through multiphoton microscopy. The

41 morphological and fluorescence analyses showed that AgNPs display different sizes, with larger nanoparticles retained

42 in fungal cell walls while smaller AgNPs penetrate into fungal cells. Probably, apoplastic and symplastic mechanisms

43 involved in the accumulation and transport of AgNPs affect the metabolic processes of the fungus, thus inhibiting its

44 growth. These results suggest that AgNPs possess antifungal activity and can be used in the eradication of contaminants

45 during the in-vitro culture of plant species.

47 Key words: nanobiotechnology, silver nanoparticles, transmission electron microscopy, antifungal activity. 
62 Plant tissue culture (PTC) is a biotechnological technique used for the in-vitro conservation, handling, sanitation, and

63 propagation of edible, medicinal, and ornamental plants. In-vitro propagation, or micropropagation, represents a

64 commercial alternative to produce pathogen-free plants (Efferth 2019). The success of micropropagation depends on

65 ensuring strict asepsis. However, microbial contamination may occur during the micropropagation of plants, leading

66 to important losses of plant material in vitro (Medjemem et al. 2016).

67

PTC contamination may be due to endophyte microorganisms, anthropogenic factors, tolerance of microorganisms to autoclaving, and resistance to antibiotics and fungicides (Thomas et al. 2017; Chechi et al. 2019; Marjon et al. 2019). In-vitro contaminants can affect the growth of explants by competing for water, light, space, and essential nutrients (Javed et al. 2017; Khan et al. 2018). In addition, the presence of contaminants limits the phytosanitary certification of PTC plant material (Sastry et al. 2014; Whattam et al. 2014). Phytosanitary certification is a priority issue in government policies in relation to economic income from the exportation and importation of in vitro plants of commercial interest (Whattam et al. 2014; Eschen et al. 2015).

There are several techniques for contamination control in micropropagated plants. One of them involves the treatment of parent plants and explants by adding fungicides and antibiotics to the culture medium (Cassells 2012). Nonetheless, the addition of antibiotics or fungicides to the culture medium for controlling bacterial contamination is not recommended due to the resistance of some strains (Caniça et al. 2019; Chechi et al. 2019). Biofilms with microbicidal effect are also available and can be used to prevent contamination, such as Plant Preservative Mixture ${ }^{\circledR}$ (PPM) and Vitrofural ${ }^{\circledR}(\mathrm{G} 1)$; however, their limited availability restrain their commercial application. An alternative for the eradication of in-vitro contaminants is the use of silver nanoparticles (AgNPs). These have been used as antimicrobial agents for the in-vitro culture of various plant species (Spinoso-Castillo et al. 2017; Tung et al. 2018).

The mechanisms of action of AgNPs as antifungal agent have not been fully elucidated because most studies have addressed antiviral and antibacterial properties (Pařil et al. 2017; Khezerlou et al. 2018).

The culture of Stevia (Stevia rebaudiana Bertoni) is of high commercial value because of the non-caloric steviosides and rebaudiosides contained in its leaves (Debnath et al. 2019; Rouhani et al. 2019). The commercial propagules currently produced are insufficient given the low percentage of seed germination and the reduced number of cuttings 
that adapt to soil (Angelini et al. 2018). The in-vitro propagation of this species is affected by spontaneous contamination after its establishment and during subculture. For this reason, it is necessary to develop micropropagation systems for this species to ensure the production of plants that are free of diseases and pathogens. The objective of this study was the identification and control of contamination during the in-vitro establishment of $S$. rebaudiana using silver nanoparticles.

\section{Materials and Methods}

Physicochemical characterization of silver nanoparticles by transmission electron microscopy

The AgNPs used in this study, formulated as Argovit ${ }^{\circledR}$, were provided by the Production Centre Vector-Vita Ltd, located in Novosibirsk, Russia. Argovit ${ }^{\circledR}$ is made up of $12 \mathrm{mg} \mathrm{mL}^{-1}$ of metallic silver and $188 \mathrm{mg} \mathrm{mL}^{-1}$ of polyvinylpyrrolidone (PVP, 15-30 kD). The morphology of nanoparticles was examined under a Philips/FEI Morgagni M-268 transmission electron microscope (Brno, Czech Republic). For the morphological analysis, $5 \mu \mathrm{L}$ of particles in suspension were mounted on a copper grid of Formvar 300 mesh/carbon (Electron Microscopy Science, PA). Samples were dried at room temperature for $5 \mathrm{~min}$. The operating conditions in all experiments were: high voltage (EHT) of $80 \mathrm{kV}$, high magnification of 1000-140000X, and working pressure of $5 \times 10^{-3} \mathrm{~Pa}(5 \times 10-5$ Torr). Micrographs were captured in tagged image file (.tif) format with a resolution of 1376 x 1032 pixels and a grey scale. In this format, 0 was assigned to black and 255 to white in the grey scale.

\section{Plant Material}

The explants used were nodal segments of stevia (Stevia rebaudiana Bertoni cv. Morita II) measuring $2 \mathrm{~cm}$ in length that contained one axillary bud. The explants were disinfected with a surfactant solution (Tween-20/distilled water) and washed with a slow flow of running water for 30 minutes. Subsequently, in a laminar flow hood, explants were immersed in $70 \%(\mathrm{v} / \mathrm{v})$ ethanol for $30 \mathrm{~s}$ and in $0.6 \%$ and $0.3 \%(\mathrm{v} / \mathrm{v})$ sodium hypochlorite for 10 and $5 \mathrm{~min}$, respectively. Three rinses with sterile water were performed. Finally, the explants were transferred to test tubes containing MS medium (Murashige and Skoog 1962), supplemented with $1 \mathrm{mg} \mathrm{L}^{-1} \mathrm{BA}$ (Bencilademina, SigmaAldrich, St. Louis, MO), $30 \mathrm{~g} \mathrm{~L}^{-1}$ sucrose, and $2.5 \mathrm{~g} \mathrm{~L}^{-1}$ Phytagel $^{\mathrm{TM}}$ (Sigma-Aldrich, St. Louis, MO). The $\mathrm{pH}$ of the media was adjusted to $5.8 \pm 0.2$. The tubes with culture medium were autoclaved at $124 \mathrm{KPa}$ for $15 \mathrm{~min}$. Cultures were incubated at $25 \pm 2{ }^{\circ} \mathrm{C}$ with a $16 / 8 \mathrm{~h}$ photoperiod (light/dark), under an irradiation of $40-50 \mu \mathrm{mol} \mathrm{m}^{-2} \mathrm{~s}^{-1}$ provided by fluorescent lamps. Subsequently, the explants showing evidence of contamination were isolated. 
Isolation and culture of the fungus Sordaria tomento-alba

120 Discs with mycelia from contaminated explants were transferred with a scalpel to Petri dishes containing potato dextrose agar medium (PDA) (Sigma-Aldrich, St. Louis, MO). Subsequently, these discs were incubated at $27{ }^{\circ} \mathrm{C}$ for

12272 hours.

Molecular identification of contaminating microorganisms

DNA extraction, PCR amplification, and ITS sequencing

126 Genomic DNA was extracted from fungal mycelium using an alkaline lysis method (Doyle and Doyle 1987). DNA

127 quality was measured using a Nanodrop ${ }^{\circledR}$ ND-1000 spectrophotometer (Thermo Scientific, Wilmington, USA).

128 Polymerase chain reaction (PCR) was performed using universal internal transcribed spacers (ITSs): ITS4 (5'-

129 TCCTCCGCTTATTGATATGC-3') and ITS5 (5'- GGAAGTAAAAGTCGTAACAAGG-3') primers (White et al.

130 1990). The PCR final volume of the reactions was $20 \mu$ l, containing $50 \mathrm{ng}$ of genomic DNA, $1 \mathrm{X}$ of PCR buffer

131 (Invitrogen, EU), $0.8 \mathrm{mM}$ of dNTPs (Invitrogen, EU), $3 \mathrm{mM} \mathrm{MgCl}_{2}, 0.5 \mu \mathrm{M}$ of each primer and $1 \mathrm{U}$ of Taq DNA

132 Polymerase (Invitrogen, EU). DNA amplification was performed in a GeneAmp ${ }^{\circledR}$ PCR System 9700 thermal cycler

133 (Perkin-Elmer). PCR parameters consisted of one cycle of initial denaturation at $90{ }^{\circ} \mathrm{C}$ for $30 \mathrm{~s}$, followed by 35

134 cycles of denaturation at $90{ }^{\circ} \mathrm{C}$ for $15 \mathrm{~s}$, primer annealing at $56{ }^{\circ} \mathrm{C}$ for $30 \mathrm{~s}$, elongation at $72{ }^{\circ} \mathrm{C}$ for $1 \mathrm{~min}$, and a final

135 elongation at $72{ }^{\circ} \mathrm{C}$ for $7 \mathrm{~min}$. The amplification products were separated by electrophoresis in $1.2 \%(\mathrm{w} / \mathrm{v})$ agarose

136 gel previously stained with ethidium bromide. The run was performed in TAE $1 \mathrm{X}$ buffer (Tris-Acetic acid-EDTA) at

$137100 \mathrm{~V}$ for $45 \mathrm{~min}$. PCR products were sequenced at the Colegio de Postgraduados (Campus Montecillo) using the

138 HiSeq 2500® Sequencing System - Illumina (Sanger method). PCR products were sequenced at the Colegio de

139 Postgraduados (Campus Montecillo) using the HiSeq $2500^{\circledR}$ Sequencing System - Illumina (Sanger method).

Multiple sequence alignment and phylogenetic tree construction

141 ITS4/ITS5 rDNA from the 16-166-H strain was used as query sequence and compared against the NCBI database

142 using the BLAST nucleotide search tool (https://blast.ncbi.nlm.nih.gov/Blast.cgi) (Altschul et al., 1997). An in-silico

143 analysis was developed with 15 target sequences producing significant alignments, using the Colletotrichum

144 acutatum (MH865675) sequence as outgroup control. The multiple sequence alignment was performed using the

145 ClustalW algorithm in the msa package (version 1.16.0) from the R program (Bodenhofer et al. 2015). For the

146 phylogenetic analysis, the ape package (version 5.3) was employed (Paradis and Schliep 2019). The phylogenetic 
147 relations of samples were constructed using the Neighbor-Joining method, and the genetic distances were computed 148 using the Jukes-Cantor method (Jukes and Cantor 1969; Saitou and Nei 1987). The optimal tree was generated with

1491000 bootstrap replicates. Bootstrap support threshold equal or greater than $50 \%$ was considered significant.

150 Graphical tree representation was plotted with the ggtree package (Yu et al 2017).

Inhibition of fungal growth

153 The antimicrobial activity of AgNPs on the growth of S. tomento-alba was explored using mycelia seeded in plates 154 with PDA and evaluating different concentrations of $\operatorname{AgNPs}\left(0,25,50,100\right.$, and $\left.200 \mathrm{mg} \mathrm{L}^{-1}\right)$. First, the culture medium was adjusted to a pH of 6.5 and was sterilized at $124 \mathrm{KPa}$ por $15 \mathrm{~min}$. Then, all treatments were inoculated with $1 \mathrm{~cm}^{2}$ of fresh mycelium of $S$. tomento-alba and incubated under a photoperiod of 18/6 hours of light/darkness, at $23-25{ }^{\circ} \mathrm{C}$. After 5 days of incubation, the variable to measure was fungus growth in diameter (known as GD), with the average of three measurements (in $\mathrm{cm}$ ) considered as GD. The growth of S. tomento-alba was evaluated after 21 days of incubation.

For the fungus growth in diameter $(\mathrm{cm})$, a completely randomized design was used, as described below:

$$
y_{i j}=\mu+\operatorname{conc}_{i}+\operatorname{rep}(\operatorname{conc})_{j(i)}+\varepsilon_{i j}
$$

Where $y_{i j}$ is fungus diameter observed at concentration $i$ of AgNPs in replicate $j ; \mu$ is the overall mean; conc $_{i}$ is the fixed effect of concentration $i$ of AgNPs; $\operatorname{rep}(\operatorname{conc})_{j(i)}$ is the random effect of replicate $j$ nested on concentration $i$ of AgNPs assuming $\operatorname{rep}(\mathrm{conc})_{j(i)} \sim N\left(0, \sigma_{\text {rep (conc) })}^{2}\right)$; and $\varepsilon_{i j}$ is the experimental error with $\varepsilon_{i j} \sim N\left(0, \sigma^{2}\right)$. Fungus growth was analyzed with the procedure PROC GLIMMIX of SAS (version 9.4) under a Generalized Linear Mixed

169 Model with Poisson distribution, and for fungus growth, Linear Mixed model was used.

172 AgNPs were detected using modifications of the "Lambda" method for determining the native spectral emission of 173 AgNPs (Castro-González et al. 2019). The nanoparticles accumulated in hyphae were visualized with a multiphoton microscopy system (Axio Imager Z2, LSM 880-NLO, Zeiss, Oberkochen, Germany) coupled to a Ti: Sapphire 
175 infrared laser (Chameleon Vision II, COHERENT, Santa Clara, CA, USA) with a tuning capability in the range of

176690 to $1060 \mathrm{~nm}$. In all experiments, the operating conditions involved the use of a Chameleon laser set at $850 \mathrm{~nm}$

177 with $1.5 \%$ power, pinole at 600.1, and similar photodetector voltage ranges. Emissions from AgNPs were recovered

178 at 596-637 nm. Images of hyphae were captured with a 63X/1.40 immersion objective, and NA $\infty-0.17$, using a

179 Zeiss Plan NEOFLUAR with a $5 \mathrm{~nm}$ spectral sensitivity. All micrographs were captured in CZI format in a size of

$1801131 \times 1131$ pixels composed of three color channels (RGB).

\section{Results}

Physicochemical characteristics of Argovit ${ }^{\circledR}$

184 The physicochemical characteristics of AgNPs are shown in Table 1. The AgNPs characterized by TEM are 185 spherical with a form factor of (0.82) and roundness of 0.88. The analysis of AgNP dimensions showed average diameters of $35 \pm 15 \mathrm{~nm}$, which consists of clustered silver (12 mg/mL metallic silver) functionalized with 188 $\mathrm{mg} / \mathrm{mL}$ of polyvinylpyrrolidone (PVP, 10-30 kD). The results obtained evidence the structural dimensions of AgNPs $\left(\right.$ Argovit $\left.{ }^{\circledR}-\mathrm{CP}\right)$ in terms of shape and size. The size of AgNPs was verified by TEM, showing macroscopic aggregates composed of silver nanoparticles. The TEM micrograph (Figure 1) corroborates the tendency to aggregate; NPs of

\section{Molecular identification of the 16-166-H fungal strain}

The BLAST algorithm-based analysis of the 560-bp ITS sequence showed that this fungal strain had a high percent identity value (96.64\%) to Sordaria strains JN207345, JN207271, and JN207268, which are associated to Sordaria tomento-alba as reported by Loro et al. 2012. Moreover, these results were confirmed by the phylogenetic tree analysis. The topology of the phylogenetic tree showed the formation of 5 clades. Among these clades, Sordaria and Asordaria species were grouped in three internal clades (Fig. 2). Clade I comprises Sordariomycetes sp., Sordaria fimicola, and Sordaria fimicola; Clade II comprises Sordaria tomento-alba and related Sordaria strains (including 16-166-H); finally, Clade III comprises Sordaria sp., Asordaria prolifica, and Asordaria conoidea. Both results reveal insights into the molecular identification of the fungal isolate. For this analysis, a reference strain was deposited in Genbank (https://www.ncbi.nlm.nih.gov/genbank/). 
The results show the fungicidal effect of AgNPs on the growth of S. tomento-alba in solid culture medium. AgNP concentrations of at least $50 \mathrm{mg} \mathrm{L-1}$ produced a significant inhibition on fungal growth (Fig. 3). The highest greatest fungal GD was observed at 0 and $25 \mathrm{mg} \mathrm{L}^{-1} \mathrm{NPsAg}$, with $7.00 \pm 0.54$ and $7.60 \pm 0.34 \mathrm{~cm}$ in diameter, respectively, whereas the lowest occurred at $200 \mathrm{mg} \mathrm{L}^{-1}$, with $2.50 \pm 0.05 \mathrm{~cm}$ (Fig. 4). For 50 and $100 \mathrm{mg} \mathrm{L}^{-1}$, no significant differences were observed in the development of the fungus, recording an average diameter of $4.30 \pm 0.60$ and $4.13 \pm$ $0.41 \mathrm{~cm}$, respectively. (Fig. 3).

Detection and effect of AgNPs on fungal growth inhibition by fluorescence microscopy

212 Multiphoton microscopy allowed observing the presence of AgNPs in fungus cells. It evidenced the presence of 213 AgNPs in the cell wall of hyphae (cross-section) subjected to the different treatments with NPs. However, as AgNP 214 concentration increased, nanoparticles showed a trend to accumulate in the space between the cell wall and the cell

215 membrane. The sequence of images in Fig. 5 shows the clear field and fluorescence of AgNPs and the progression of 216 fluorescence in stem cross-sections under different treatments with AgNPs.

\section{Discussion}

219 This study evidenced the antifungal effect of AgNPs on the fungus S. tomento-alba during the in-vitro establishment of S. rebaudiana. S. tomento-alba has been reported as an endophyte in various plant species, including

221 Stryphnodendron adstringens (Carvalho et al. 2012), Cenchrus ciliaris, and Cenchrus cf. spinifex Cav. (Loro et al.

222 2012), and in different cultivars of Solanum tuberosum (Zimudzi et al. 2017). Although this fungus is not reported as

223 a phytopathogen, it causes contamination issues in in-vitro Stevia cultures. The effectiveness of AgNPs in the

224 elimination of microbial contaminants from in-vitro cultures depends on AgNP size, shape, and type of coating. With 225 regard to the characterization of Argovit ${ }^{\circledR}$, the TEM allowed us to observe particles of $40 \pm 10 \mathrm{~nm}$ in size, with the 226 dominance of a spheroid form factor (0.80). The toxicity of AgNPs in biological systems has been reported to be 227 inversely proportional to particle size (i.e., smaller particles are more toxic) (Panzarini et al. 2018).

228 The analysis of the ITS sequence of the fungal strain 16-166-H supported its identification as belonging to the genus 229 Sordaria, genetically related to the species S. tomento-alba. The molecular identification of contaminants is relevant 230 because it allows knowing its origin and deriving an appropriate treatment for the disinfection of explants (Tomasi et 
231 al. 2017). In this study, it was found that $S$. tomento-alba is a non-phytopathogenic endophyte. However, it can

232 lead to contamination in the in-vitro establishment of S. rebaudiana and, if uncontrolled, may spread across the

233 laboratory and affect other species cultured in vitro. The AgNPs used in this study probably affect the growth of

234 species of the genus Sordaria (Sordaria spp.). In general, in-vitro contaminants first use the carbon available

235 within the plant to survive; subsequently, they migrate to the culture medium that is rich in nutrients and

236 contains sucrose as carbon source. The fungi in the culture medium compete with explants for space, water,

237 light, and nutrients, causing the death of explants (Cassells 2012; Tomasi et al. 2017). One option to eradicate

238 these microorganisms is through the culture of meristems, thermotherapy, and use of antifungal agents

239 (Cassells 2012; Smith 2013: Sasi and Bhat 2018). The culture of meristems has been used primarily to eradicate

240 viruses (Sasi and Bhat, 2018); for its part, thermotherapy occasionally damages the explants (Hu et al. 2019; Kaur et

241 al. 2019). As regards the use of antifungal agents, these can lead to the development of resistance in some fungal

242 strains (Caniça et al. 2019; Chechi et al. 2019). AgNPs do not exert selective pressure on microorganisms and,

243 therefore, do not lead to resistance (Lemire et al. 2013; Khezerlou et al. 2018); thus, these may be less toxic than

244 synthetic fungicides.

246 In our study, during the inhibition of the growth of S. tomento-alba, we noted that AgNP concentrations of 50 and

$247100 \mathrm{mg} \mathrm{L}^{-1}$ correspond to the half maximal inhibitory concentration $\left(\mathrm{IC}_{50}\right)$. An antifungal effect of $\mathrm{AgNPs}$ has been

248 reported for different fungi strains. Jo et al. (2009) mention that AgNP concentrations from $200 \mathrm{mg} \mathrm{L}^{-1}$ were needed

249 to control the development of spores of Bipolaris sorokiniana and Magnaporthe grisea. On the other hand, Pulit et

250 al. (2013) demonstrated the inhibition of the growth of Cladosporium cladosporioides and Aspergillus niger strains

251 at $50 \mathrm{mg} \mathrm{L}^{-1} \mathrm{AgNPs}$. Kim et al. (2009) observed that $25 \mathrm{mg} \mathrm{L}^{-1}$ of AgNPs affect the integrity of the structure of

252 hyphae of Raffaelea spp., while Kasprowicz et al., (2010) noted that $10 \mathrm{mg} \mathrm{L}^{-1}$ of AgNPs reduce the radial growth of

253 Fusarium culmorum. Moreover, AgNP concentrations from $2.5 \mathrm{mg} \mathrm{L}^{-1}$ drastically reduce the germination of spores.

254 Recently, Ruiz-Romero et al. (2018) used AgNPs to inhibit the radial growth of two phytopathogenic fungi

255 (Fusarium solani and Macrophomina phaseolina). However, this work only mentions that the AgNPs supplemented

256 were obtained as an extract from Yucca (Yucca shilerifera), without reporting the AgNP concentration. Also, the

257 physicochemical characteristics of AgNPs are not reported in the studies mentioned above. It is our opinion that

258 AgNPs should be characterized before conducting a research study. 
259 The microbicidal effect of AgNPs derives from the interaction of silver ions with a broad range of molecular and metabolic processes within organisms, including growth inhibition, cell death, and inhibition of DNA replication (Abdi et al. 2008; Yun'an Qing et al. 2018). In fungi, AgNPs break the cell membrane of hyphae, thus impairing infection mechanisms (Kim et al. 2008; Bocate et al. 2019) and inhibiting the germination of conidia (Kim et al. 2009). In our study, we observed the accumulation of AgNPs in the cell wall and cytoplasm of hyphae of S. tomentoalba. The exact mechanism of transport and accumulation of AgNPs in fungi is currently unknown. However, the results of the characterization of AgNPs suggest that due to diversity of sizes (2-85 nm), larger nanoparticles accumulate in the cell wall and cell membrane, affecting the integrity of these organelles; for their part, smaller nanoparticles penetrate through pores in the cell wall and the cell membrane via transport by plasmodesmata. According to Money (1990), cell membrane pore size in hyphae of some fungi ranges from 2.3-3.3 nm, which could explain the penetration of small nanoparticles. AgNPs that manage to penetrate inside the cell cause an increase of

$270 \mathrm{Ag}+$ cations, which could affect the electrical potential of the membrane. According to Srikar et al. (2016) and

271 Khezerlou et al. (2018), these Ag+ ions denaturate proteins, deplete intracellular ATP, and form complexes with

272 DNA bases, so that the DNA loses its replication ability. On the other hand, the reaction of Ag + with thiol,

273 carboxylate, phosphate, hydroxyl, amine, imidazole, and indole groups in enzymes may lead to their inactivation and

274 cell death (Lin et al. 1998; Ashraf et al. 2013). The Ag+ in nanoparticles probably exerts important effects on

275 biological systems. The use of AgNPs for disease control has the advantage of being non-toxic to humans and the

276 environment, unlike synthetic pesticides.

278 In conclusion, the AgNPs used in this study showed an antifungal effect in S. tomento-alba, a common contaminant 279 during the establishment of S. rebaudiana. AgNPs with similar physicochemical characteristics may be used to 280 control other fungal strains that contaminate in-vitro cultures. Therefore, further studies should be conducted on the 281 microbicidal potential of AgNPs in the micropropagation of different plant species, and the effects of AgNPs on 282 DNA damage and replication.

\section{Conflict of interest}

285 The authors declare that they have no conflicting interests. 
SLH and JJBB devised and designed this research. SLH and LSS conducted the experiments. MARM and EBB reviewed and approved the manuscript.

\section{References}

Abdi G, Salehi H, Khosh-Khui M (2008) Nano silver: a novel nanomaterial for removal of bacterial contaminants in valerian (Valeriana officinalis L.) tissue culture. Acta Physiol Plant 30: 709-714. https://doi.org/10.1007/s11738-008-0169-z

Altschul SF, Madden TL, Schaffer AA, Zhang J, Zhang Z, Miller W, Lipman DJ (1997) Gapped BLAST and PSIBLAST: a new generation of protein database search programs. Nucleic Acids Res 25:3389-3402. https://doi.org/10.1093/nar/25.17.3389

Angelini LG, Martini A, Passera B, Tavarini S (2018) Cultivation of Stevia rebaudiana Bertoni and Associated Challenges. In: Mérillon JM., Ramawat K. (eds) Sweeteners. Reference Series in Phytochemistry. Springer, Cham. https://doi.org/10.1007/978-3-319-27027-2_8

Ashraf S, Abbasi AZ, Pfeiffer C, Hussain SZ, Khalid ZM, Gil PR, Parak WJ, Hussain I (2013) Protein-Mediated Synthesis, pH-Induced Reversible Agglomeration, Toxicity and Cellular Interaction of Silver Nanoparticles. Colloid Surf B-Biointerfaces 102 (2013) 511-51. https://doi.org/10.1016/j.colsurfb.2012.09.032

Bodenhofer U, Bonatesta E, Horejš-Kainrath C, Hochreiter S (2015). msa: an R package for multiple sequence

Caniça M, Manageiroa V, Abriouel H, Moran-Gilad J (2019) Antibiotic resistance in foodborne bacteria. Trends alignment. Bioinformatics 31:3997-3999. https://doi.org/10.1093/bioinformatics/btv494 Food Sci Technol. 84:41-44. https://doi.org/10.1016/j.tifs.2018.08.001

Bocatea KP, Reisa GF, de Souzaa PC, Oliveira Junior AG, Durán N, Nakazatoa G, Furlanetoa MC, de Almeida RC, Panagio LA (2019) Antifungal activity of silver nanoparticles and simvastatin against toxigenic species of Aspergillus. Int J Food Microbiol 291:79-86. https://doi.org/10.1016/j.ijfoodmicro.2018.11.012

Carvalho CR, Gonçalves VN, Pereira CB, Johann S, Galliza IV, Alves TMA, Rabello A, Sobral MAG, Zani CL, Rosa CA, Rosa LH (2012) The diversity, antimicrobial and anticancer activity of endophytic fungi associated with the medicinal plant Stryphnodendron adstringens (Mart.) Coville (Fabaceae) from the Brazilian savannah. Symbiosis 57:95-107. https://doi.org/10.1007/s13199-012-0182-2 
Cassells A.C. (2012) Pathogen and Biological Contamination Management in Plant Tissue Culture: Phytopathogens, Vitro Pathogens, and Vitro Pests. In: Loyola-Vargas V., Ochoa-Alejo N. (eds) Plant Cell Culture Protocols. Methods in Molecular Biology (Methods and Protocols), vol 877. Humana Press, Totowa, NJ. https://doi.org/10.1007/978-1-61779-818-4_6

Hu G, Dong Y, Zhang Z, Fan X, Ren F (2019) Elimination of apple necrosis mosaic virus from potted apple plants by thermotherapy combined with shoot-tip grafting. Sci Hortic 252:310-315. https://doi.org/10.1016/j.scienta.2019.03.065

Javed SB, Alatar AA, Basahi R, Anis M, Faisal M, Husain FM (2017) Copper induced suppression of systemic microbial contamination in Erythrina variegata L. during in vitro culture. Plant Cell Tissue Organ Cult 128:249-258. https://doi.org/10.1007/s11240-016-1104-4

Jo YK, Kim BH, Jung G (2009) Antifungal Activity of Silver Ions and Nanoparticles on Phytopathogenic Fungi. Plant Dis 93:1037-1043. https://doi.org/10.1094/PDIS-93-10-1037

Jukes TH and Cantor CR (1969). Evolution of protein molecules. In Munro HN, editor, Mammalian Protein

Metabolism, pp. 21-132, Academic Press, New York. https://doi.org/10.1016/B978-1-4832-3211-9.50009-7

Kasprowicz MJ, Kozioł M, Gorczyca A (2010) The effect of silver nanoparticles on phytopathogenic spores of Fusarium culmorum. Can J Microbiol 56:247-253. https://doi.org/10.1139/W10-012

Kaur C, Raj R, Kumar S, Purshottam DK, Agrawal L, Chauhan PS, Raj SK (2019) Elimination of Bean yellow mosaic virus from infected cormels of three cultivars of gladiolus using thermo-, electro- and chemotherapy. 3 Biotech 9:154. https://doi.org/10.1007/s13205-019-1684-x

Khan T, Abbasi BH, Iqrar I,Khan MA, Shinwari ZK (2018) Molecular identification and control of endophytic contamination during in vitro plantlet development of Fagonia indica. Acta Physiol Plant. (2018) 40:150. https://doi.org/10.1007/s11738-018-2727-3

Khezerlou A, Alizadeh-Sanib M, Azizi-Lalabadib M, Ehsanic A (2018) Nanoparticles and their antimicrobial properties against pathogens including bacteria, fungi, parasites and viruses. Microb Pathog 123:505-526. https://doi.org/10.1016/j.micpath.2018.08.008

Kim KJ, Sung WS, Moon SK, Choi JS, Kim JG, Lee DG (2008) Antifungal effect of silver nanoparticles on dermatophytes. J Microbiol Biotechnol 18:1482-1484. 
Kim SW, Kim KS, Lamsal K, Kim YJ, Kim SB, Jung M, Sim SJ, Kim HS, Chang SJ, Kim JK, Lee YS (2009) An In Vitro Study of the Antifungal Effect of Silver Nanoparticles on Oak Wilt Pathogen Raffaelea sp. J Microbiol Biotechnol 19:760-764. https://doi.org/10.4014/jmb.0812.649

Lemire JA, Harrison JJ, Turner RJ (2013) Antimicrobial activity of metals: mechanisms, molecular targets and applications. Nat Rev Microbiol 11:371-384. https://doi.org/10.1038/nrmicro3028

Lin YE, Vidic RD, Stout JE, Mccartney CA, Yu VL (1998) Inactivation of Mycobacterium avium by copper and silver ions. Water Res 32:1997-2000. https://doi.org/10.1016/S0043-1354(97)00460-0

Loro M, Valero-Jimenez CA, Nozawa S, Marquez LM (2012) Diversity and composition of fungal endophytes in semiarid Northwest Venezuela. J Arid Environ 85: 46-55. https://doi.org/10.1016/j.jaridenv.2012.04.009

Medjemem M, Harabi A, Bouzerara F, Foughali L, Boudaira B, Guechi A, Brihi N (2016) Elaboration and characterization of low cost ceramics microfiltration membranes applied to the sterilization of plant tissue culture media. J Taiwan Inst Chem Eng 59:79-85. http://dx.doi.org/10.1016/j.jtice.2015.07.032

Money NP (1990) Measurement of Pore Size in the Hyphal Cell Wall of Achlya bisexualis. Exp Mycol 14:234-242. https://doi.org/10.1016/0147-5975(90)90021-K

Murashige T, Skoog F (1962) A revised medium for rapid growth and bioassays with tobacco tissue cultures. Physiol Plant 15:473-497. https://doi.org/10.1111/j.1399-3054.1962.tb08052.x

Panzarini E, Mariano E, Carata E, Mura F, Rossi M, Dini L (2019) Intracellular Transport of Silver and Gold Nanoparticles and Biological Responses: An Update. Int J Mol Sci 19:305. https://doi.org/10.3390/ijms19051305

Paradis E, Schliep K (2019). ape 5.0: an environment for modern phylogenetics and evolutionary analyses in R. Bioinformatics 35:526-528. https://doi.org/10.1093/bioinformatics/bty633

Pařil P, Baar J, Čermá P, Rademacher P, Prucek R, Sivera M, Panácč A (2017). Antifungal effects of copper and silver nanoparticles against white and brown-rot fungi. J Mater Sci 52:2720-2729. https://doi.org/10.1007/S10853-016-0565-5

Pulit J, Banach M, Szczygłowska R, Bryk M (2013) Nanosilver against fungi. Silver nano-particles as an effective stevioside from Stevia Rebaudiana. Ind Crop Prod 132:226-235. https://doi.org/10.1016/j.indcrop.2019.02.029 
Ruiz-Romero P, Valdez-Salas B, González-Mendoza D, Mendez-Trujillo V (2018). Antifungal Effects of Silver Phytonanoparticles from Yucca shilerifera Against Strawberry Soil-Borne Pathogens: Fusarium solani and Macrophomina phaseolina. Mycobiology 46:47-51. https://doi.org/10.1080/12298093.2018.1454011

Saitou N and Nei M (1987). The neighbor-joining method: A new method for reconstructing phylogenetic trees. Mol Biol Evol 4:406-425. https://doi.org/10.1093/oxfordjournals.molbev.a040454

Sasi S, Bhat AI (2018) In vitro elimination of Piper yellow mottle virus from infected black pepper through somatic embryogenesis and meristem-tip culture. Crop Prot 103:39-45. http://dx.doi.org/10.1016/j.cropro.2017.09.004

Sastry KS, Zitter TA, Management of Virus and Viroid Diseases of Crops in the Tropics. In: Plant Virus and Viroid Diseases in the Tropics. Springer, Dordrecht. https://doi.org/10.1007/978-94-007-7820-7_2

Smith RH (2013) Meristem Culture for Virus-Free Plants. In: Smith RH (ed) Plant Tissue Culture (Third Edition), Academic Press, Pp. 119-126. https://doi.org/10.1016/B978-0-12-415920-4.00011-6.

Spinoso- Castillo JL, Chavez- Santoscoy RA, Bogdanchikova N, Perez- Sato JA, Morales- Ramos V, Bello- Bello JJ (2017). Antimicrobial and hormetic effects of silver nanoparticles on in vitro regeneration of vanilla (Vanilla planifolia Jacks. Ex Andrews) using a temporary immersion system. Plant Cell Tissue Organ Cult 129:195-207. https://doi.org/10.1007/s11240-017-1169-8

Srikar S, Giri D, Pal D, Mishra P, Upadhyay S (2016) Green Synthesis of Silver Nanoparticles: A Review. Green Sust Chem 6:34-56. http://dx.doi.org/10.4236/gsc.2016.61004

Thomas P, Agrawal M, Bharathkumar CB (2017). Use of Plant Preservative MixtureTM for establishing in vitro cultures from field plants: Experience with papaya reveals several PPMTM tolerant endophyticbacteria. Plant Cell Rep 36:1717-1730. https://doi.org/10.1007/s00299-017-2185-1

Tung HT, Nam NB, Huy NP, Luan VQ, Hien VT, Phuong TTB, Le DT, Loc NH, Nhut DT (2018) A system for large scale production of chrysanthemum using microponics with the supplement of silver nanoparticles under light-emitting diodes. Sci Hortic 232:153-161. https://doi.org/10.1016/j.scienta.2017.12.063

Wells-Bennika MHJ, Janssena PWM, Klausa V, Yanga C, Zwietering MH, Den Bestenb HMW (2019) Heat resistance of spores of 18 strains of Geobacillus stearothermophilus and impact of culturing. Int J Food Microbiol. 291:161-172. https://doi.org/10.1016/j.ijfoodmicro.2018.11.005 
Whattam M, Clover G, Firko M, Kalaris T (2014) The Biosecurity Continuum and Trade: Border Operations. In:

Gordh G., McKirdy S. (eds) The Handbook of Plant Biosecurity. Springer, Dordrecht.

400 https://doi.org/10.1007/978-94-007-7365-3 6

401

Yu G, Smith D, Zhu H, Guan Y, Lam TTY (2017). ggtree: an R package for visualization and annotation of phylogenetic trees with their covariates and other associated data. Methods Ecol Evol 8:28-36. https://doi.org/10.1111/2041-210X.12628 


\section{Tables}

Table 1. Physicochemical characteristics of Argovit ${ }^{\mathbb{B}}$

\begin{tabular}{lc}
\hline Properties & Mean \\
\hline Average diameter of metallic silver particles by TEM (nm) & $40 \pm 10$ \\
Form Factor (Spheroid) & 0.80 \\
Metallic silver content (\% wt.) & 1.2 \\
PVP Content (\% wt.) & 18.8 \\
Roundness & 0.80 \\
Size interval of metallic silver particles by TEM (nm) & $2-85$ \\
Zeta potential (mV) & -15 \\
\hline Abbreviations: Ag, silver; PVP, polyvinylpyrolidone; TEM, transmission electron \\
microscopy.
\end{tabular}

428

429

430

431

432

433

434

435

436

437

438

439

440

441

442

443

444 


\section{$446 \quad$ Legends of figures}

447 Fig. 1 Microphotographs of Argovit ${ }^{\circledR}$ AgNPs. a) Magnified TEM images of an AgNP aggregate of spherical shape 448 and several sizes in the range of 36.59-66.24 nm. Scale bar=100 nm. b) TEM micrograph of AgNP aggregates. Scale $449 \quad$ bar $=500 \mathrm{~nm}$.

451 Fig. 2 Phylogenetic tree and multiple sequence alignment of 16-166-H strain based on ITS4/ITS5 rDNA and NCBI 452 BLAST sequences. A) The phylogenetic tree was inferred from a distance analysis with the Neighbor-Joining method. 453 Colletotrichum acutatum (MH865675) was used as outgroup. B) An abstract multiple sequence alignment of 16 NCBI 454 BLAST sequences was performed with the ClustalW algorithm. Numbers at the top of the graph correspond to columns 455 in the alignment (bp). Nucleotide legends are shown at the bottom.

457 Fig. 3 Effect of different AgNP concentrations on growth of Sordaria tomento-alba in PDA medium after 21 days. 458 Bars represent the mean \pm standard error. Bars followed by different letters denote significant statistical differences 459 (Tukey, $\mathrm{p} \leq 0.05$ ).

461 Fig. 4 Growth of S. tomento-alba in PDA supplemented with different concentrations of AgNPs after 21 days of 462 incubation: a) $0 \mathrm{mg} \mathrm{L}-1$, b) $25 \mathrm{mg} \mathrm{L}-1$, c) $50 \mathrm{mg} \mathrm{L}-1$, d) $100 \mathrm{mg} \mathrm{L}-1$, and e) $200 \mathrm{mg} \mathrm{L}-1$.

464 Fig. 5 Location of AgNPs in S. tomento-alba cultured in PDA media. a-b) 0 mg L-1 AgNPs, merging and fluorescence, 465 respectively, c-b) $200 \mathrm{mg} \mathrm{L-1} \mathrm{AgNPs,} \mathrm{merging} \mathrm{and} \mathrm{fluorescence,} \mathrm{respectively.} \mathrm{Bar}=10 \mu \mathrm{m}$. 
1
20
1
2 $\ldots$
$\ldots$
$\ldots$
$\ldots$
$\ldots$
$\ldots$
$\ldots$
$\ldots$
$\ldots$
$\ldots$
$\ldots$
Colletotrichum acutatum (MH865675) Neurospora dictyophora (MH862539) Neurospora dictyophora (NR 163513) Neurospora tetraspora (NR 077163) Neurospora tetraspora (MH859381) Sordariomycetes sp. (KR093954) Sordaria fimicola (EU918704) Asordaria sibutii (MH860577) Sordaria tomento-alba (AY681195) Sordaria sp. (JN207268) Sordaria sp. (JN207345) Sordaria sp. (JN207271) Sordaria tomento-alba (16-166-H) Sordaria sp. (M G098252) Asordaria prolifica (AY681174) Asordania conoidea (MH860572)

0.25

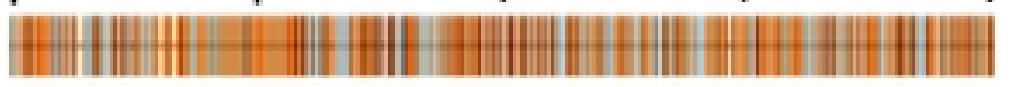
| | |

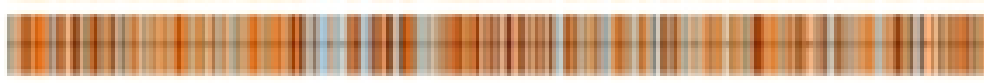

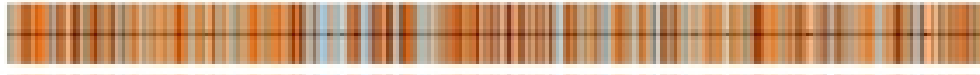
| |

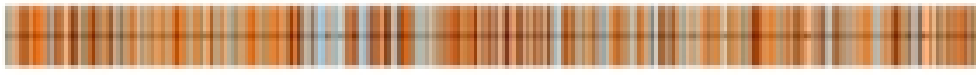
| | H. | " |

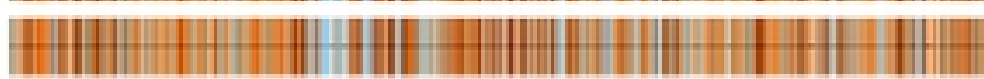
Nucleotide

\section{Figure 2}




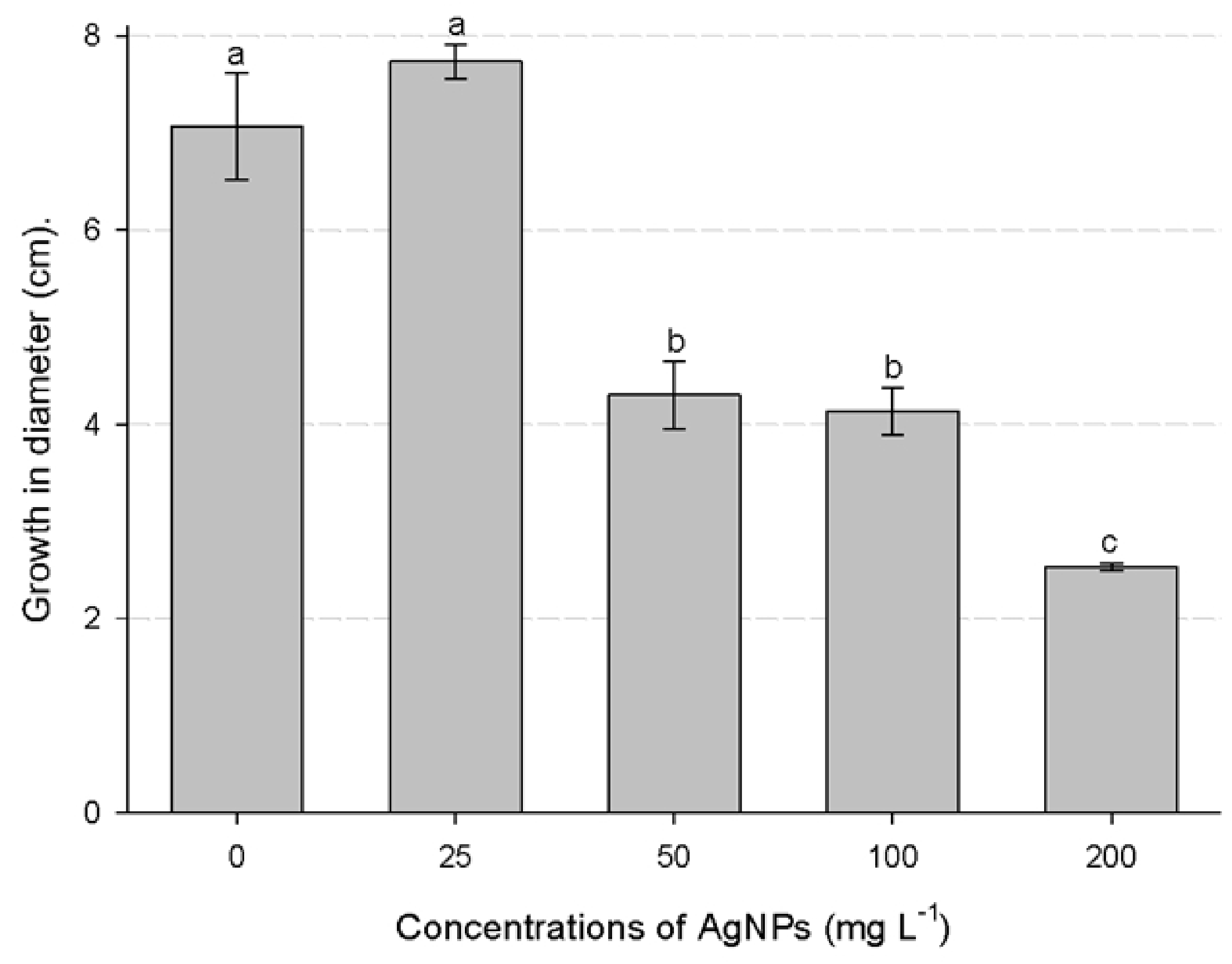

Figure 4 


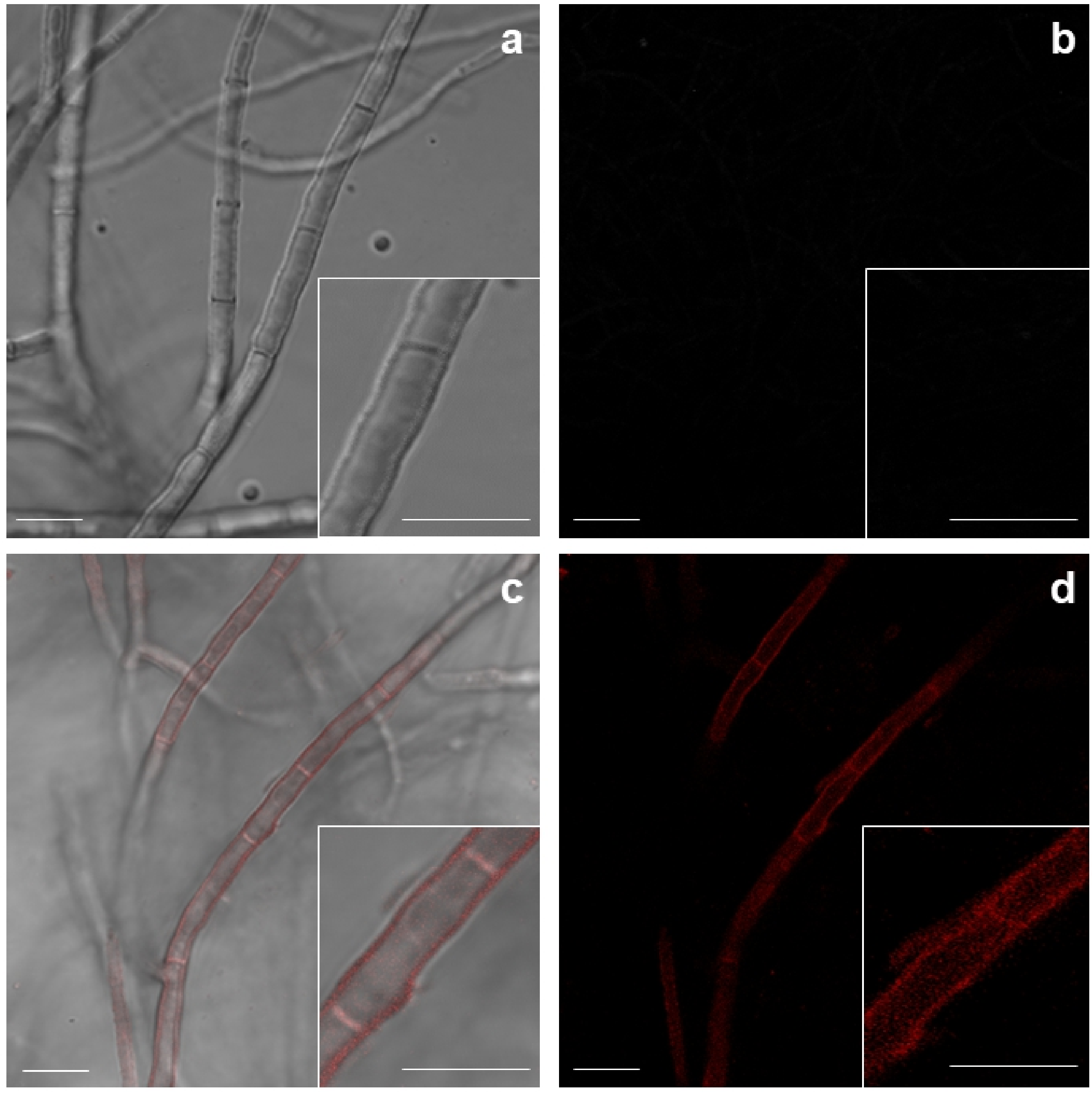

Figure 5 